\title{
Fractionation of Lignocellulosic Biomass using the OrganoCat Process
}

\author{
Leonie Schoofs ${ }^{1}$, Dennis Weidener ${ }^{1}$, Ulrich Schurr ${ }^{1}$, Holger Klose ${ }^{1}$, Philipp M. Grande ${ }^{1}$ \\ ${ }^{1}$ Institut für Bio- und Geowissenschaften, Pflanzenwissenschaften (IBG-2), Forschungszentrum Jülich
}

\section{Corresponding Authors}

Holger Klose

h.klose@fz-juelich.de

Philipp M. Grande

p.grande@fz-juelich.de

\section{Citation}

Schoofs, L., Weidener, D., Schurr, U., Klose, H., Grande, P.M. Fractionation of Lignocellulosic Biomass using the OrganoCat Process. J. Vis. Exp. (172), e61933, doi:10.3791/61933 (2021).

\section{Date Published}

June 5, 2021

\section{DOI}

$10.3791 / 61933$

URL

jove.com/video/61933

\section{Abstract}

The shift from a petroleum-based to a more sustainable and bio-based economy requires the development of new refinery concepts to maintain the supply of raw materials and energy. For these novel and sustainable biorefinery concepts, it is important to use catalysts and solvents that are aligned with the principles of Green Chemistry. Therefore, the implementation of biogenic alternatives can be a promising solution. The lignocellulose pretreatment and fractionation process presented hereinOrganoCat-is an integrated fractionation of lignocellulose into its main components using biogenic acids such as 2,5-furandicarboxylic acid as catalyst. Hemicelluloses and other non-cellulosic polysaccharides are selectively depolymerized by the diluted acid and dissolved, while the crystalline cellulose remains in the solid pulp. In the presence of a second organic phase consisting of biogenic 2-methyltetrahydrofuran, disentangled lignin is extracted in situ. The process allows for the efficient fractionation of the three main components-lignin, cellulose, and non-cellulosic sugars. This helps to focus on the quality of the lignin, the improvement of enzymatic hydrolysis of the cellulose-enriched pulp, and the mild non-cellulosic sugar extraction with low degradation.

\section{Introduction}

The use of fossil resources has brought great technological advances as they form the basis for numerous products that are essential for everyday life. However, the limitation of resources such as oil and gas on earth and the environmental damages connected with their exploitation create an urgent need for alternatives. Lignocellulosic biomass is a promising source for carbon-based chemicals, as it is renewable, versatile, and carbon neutral ${ }^{1}$. Lignocellulose basically consists of three main fractions to make use of: hemicelluloses, cellulose, and lignin. Its industrial processing has a long history. However, established and widespread processes, such as the sulfite and Kraft processes from paper industry, mainly focus on cellulose for utilization in the pulp and paper industry ${ }^{2}$. A full valorization of all three lignocellulosic fractions is needed to make lignocellulose 
processing towards chemicals more profitable from economic and environmental perspectives.

In many lignocellulose valorization strategies, lignin is a mere byproduct that is often burned for energy recovery. Currently, only $1-2 \%$ of the industrially produced lignin is used to produce value-added products such as concrete additives, surfactants, and vanillin ${ }^{3}$. Nevertheless, it is the largest renewable source of aromatics and therefore has promising properties for application as a basis for polymers ${ }^{4}$, carbon fibers ${ }^{5}$, and fuel ${ }^{2}$. The challenges in the valorization of lignin lie in its complex structure and diversity, depending on the source material and extraction conditions. Moreover, due to their process conditions, the most prevalent lignocellulose fractionation processes deliver sulfonated lignin with a high number of $\mathrm{C}-\mathrm{C}$ linkages between the monomer units. Therefore, commercially available lignin is challenging to depolymerize.

A range of different approaches, which focus on the holistic utilization of all three fractions, have been developed for lignocellulose fractionation. Most processes rely on the hydrolysis of hemicellulose, either with diluted acids and bases or by utilizing the autoprotolysis of water at elevated temperatures. As one of the most explored options, organosolv processes use low-boiling organic solvents, usually in combination with water. Well-known variants of this process include the Alcell process, which utilizes $50 \%$ ethanol, and the Organocell process, which uses methanol in the first step and adds $\mathrm{NaOH}$ in the second step. Acid organosolv processes that use formic or acetic acid are also described ${ }^{2}$. Owing to the recent focus on the valorization of lignin as a major biorefinery product, new approaches have been developed, which combine lignin extraction with subsequent or integrated conversion steps to yield smaller lignin compounds and more stable and valuable products $^{6,7,8}$.

The OrganoCat lignocellulose fractionation process (OrganoCat) is based on a two-phase system of water and 2-methyltetrahydrofuran $(2-\mathrm{MTHF})^{9}$. Additionally, a recyclable organic acid is used as catalyst, which selectively hydrolyzes hemicelluloses at mild temperatures. All process chemicals can be produced in a relatively inexpensive and biogenic manner, which lowers the environmental impact of the process in accordance to the principles of Green Chemistry ${ }^{10}$. The process delivers three separate product streams with lignin in the organic phase, depolymerized hemicellulose sugars in the aqueous phase, and celluloseenriched pulp as a solid residue. As the product streams can be easily separated, downstream steps, energy demand, and material costs can be reduced significantly compared to, for example, monophasic approaches. The lignin has a relatively low molecular weight and a high number of $\beta-O-4$ linkages ${ }^{11}$. The depolymerized hemicellulose sugars can be used for fermentation or conversion into fine chemicals $^{12}$. The cellulose pulp is highly accessible for enzymatic depolymerization ${ }^{9}$.

The original OrganoCat process uses oxalic acid as catalyst to fractionate lignocellulose. Oxalic acid can then be recovered by crystallization ${ }^{9}$. However, this increases the process costs for cooling the reaction and the partial evaporation of water. The partial decomposition of oxalic acid would diminish the revenues further ${ }^{13}$. For this reason, the OrganoCat process was improved by introducing 2,5furandicarboxylic acid (FDCA) as catalyst ${ }^{11}$. FDCA is not only sufficiently acidic to catalyze the reaction, but can also be derived from glucose via dehydration to 5hydroxymethylfurfural and subsequent oxidation with metal- 
based catalysts or biocatalysts ${ }^{14,15,16,17}$. Although the acidity of FDCA is slightly lower, it has a higher thermal stability than oxalic acid. FDCA has a low solubility in water at room temperature, which allows its straightforward recovery from the aqueous phase after the reaction.

A scale-up of the OrganoCat process was successfully developed to a $3 \mathrm{~L}$ reactor ${ }^{18}$. Additional studies on OrganoCat lignin found that antisolvent precipitation with $n$-hexane or $n$-pentane allow an energy efficient lignin recovery ${ }^{19}$. It was possible to get lignin fractions with different molecular weights ${ }^{20}$. This paper presents the full preparative method for a scalable, one-step fractionation process of lignocellulosic biomass using FDCA as catalyst. This process yields extracted lignin, depolymerized hemicelluloses, and cellulose pulp in three easily separable product streams.

\section{Protocol}

NOTE: The process may be paused at any point by leaving the samples at room temperature (for a few days) or in the refrigerator (for longer periods). See the Table of Materials for details on the materials used in this protocol.

\section{Beech wood particles}

1. Generate the desired particle size of beech wood (Fagus sp.) using a cutting mill with a $10 \mathrm{~mm}$ sieve, and dry the particles at $50{ }^{\circ} \mathrm{C}$ to constant mass $(\sim 24 \mathrm{~h})$, leaving a residual moisture content of $\sim 10 \%$ water.

\section{Lignocellulosic fractionation and workup}

1. Lignocellulose pretreatment and fractionation

1. Suspend $500 \mathrm{mg}$ of beech wood (Fagus sp.) particles and $78.0 \mathrm{mg}(0.5 \mathrm{mmol}, 0.1 \mathrm{M})$ of FDCA in $5 \mathrm{~mL}$ of ultrapure water at room temperature in a 25
$\mathrm{mL}$ stainless steel high-pressure reactor. Add $5 \mathrm{~mL}$ of 2-MTHF and a stirring bar to the suspension, and close the reactor. Heat the reactor to $160{ }^{\circ} \mathrm{C}$ on a heating plate at a stirring speed of $1500 \mathrm{rpm}$ for $1 \mathrm{~h}$.

2. Let the reaction cool down to room temperature in ice-water over a period of $\sim 10 \mathrm{~min}$. Open the reactor, add $52.5 \mu \mathrm{L}$ of $\mathrm{NaOH}$ solution (50 wt\% $\mathrm{NaOH}$ in distilled water), and stir for 15 min at room temperature and 500 rpm on a stirring plate.

2. Isolation of organic phase and lignin quantification

1. Centrifuge the mixture (room temperature, $5 \mathrm{~min}$, $1880 \times g)$. Use a pipette to transfer the organic phase (2-MTHF) to a $50 \mathrm{~mL}$ round-bottom flask.

2. Evaporate the organic phase in a rotary evaporator (40 ${ }^{\circ} \mathrm{C}, 200 \mathrm{rpm}, 180 \mathrm{mbar}$ ) until a solid and dry lignin fraction is obtained. Determine the lignin yield by weighing with an analytical balance. Store the solid lignin at room temperature for further analysis.

3. Separation of solid cellulose-enriched pulp and aqueous phase

1. Filter the aqueous phase using a cellulose filter paper (17-30 $\mu \mathrm{m}$ pore size) in a funnel to isolate the cellulose-enriched pulp, and transfer the aqueous phase to a $5 \mathrm{~mL}$ vial. Wash the pulp until neutral $\mathrm{pH}$ with $3 \times 25 \mathrm{~mL}$ water, and store the washing solution separately in a $100 \mathrm{~mL}$ beaker. Dry the pulp at $80{ }^{\circ} \mathrm{C}$ to constant mass $(\sim 24 \mathrm{~h})$.

2. Determine the dried pulp yield by weighing with an analytical balance.

4. FDCA recovery and isolation of aqueous phase

1. Adjust the $\mathrm{pH}$ of the aqueous phase and the washing solution from step 2.3 separately under constant 
stirring to $\mathrm{pH} 1$ using concentrated $\mathrm{HCl}$ while cooling the solution in an ice bath. Control the $\mathrm{pH}$ using universal indicator paper.

2. Filter the precipitated solid (FDCA) from both solutions, combine the residues, and dry at $80^{\circ} \mathrm{C}$ to constant mass ( 24 h). Discard the washes. Determine the FDCA yield by weighing with an analytical balance.

3. Transfer the aqueous phase to a $25 \mathrm{~mL}$ flask, and store it at $4{ }^{\circ} \mathrm{C}$ for analysis.

5. Sample preparation for furfural quantification

1. Perform a separate experiment to determine the quantity of furfural. Repeat steps 2.1.1-2.2.1.

2. Add $40 \mathrm{mg}$ of $n$-decane as an internal standard to the collected organic solvent fraction, and store for analysis.

\section{Analysis}

1. Analysis of sugar in the aqueous phase by highperformance anion-exchange chromatography with pulsed amperometric detection (HPAEC-PAD)

1. Dilute $10 \mu \mathrm{L}$ of the aqueous phase collected in step 2.4.3 with $190 \mu \mathrm{L}$ of distilled water. Add $10 \mu \mathrm{L}$ of 2 $\mathrm{mM}$ 2-deoxy-D-glucose to the diluted sample.

2. Perform the separation of monosaccharides on a monosaccharide separator column with a flow rate of $0.5 \mathrm{~mL} \cdot \mathrm{min}^{-1}$, and inject the sample after equilibration with $2 \mathrm{mM} \mathrm{NaOH}$ for $10 \mathrm{~min}$. Separate the neutral sugars with $2 \mathrm{mM} \mathrm{NaOH}$ over $18 \mathrm{~min}$. Afterwards, use $550 \mathrm{mM} \mathrm{NaOH}$ for $10 \mathrm{~min}$ to separate the uronic acids. Rinse the column with 800 $\mathrm{mM} \mathrm{NaOH}$ for $10 \mathrm{~min}$.
NOTE: The software normalizes the amounts of monosaccharides to the amount of the internal standard and quantifies them by using standard calibration curves of the different monosaccharides.

2. Lignin analysis via ${ }^{1} \mathrm{H}-{ }^{13} \mathrm{C}$ heteronuclear single quantum correlation nuclear magnetic resonance $\left({ }^{1} \mathrm{H}-{ }^{13} \mathrm{C}-\mathrm{HSQC}\right.$ NMR)

1. Dissolve $\sim 50 \mathrm{mg}$ of lignin in $0.5 \mathrm{~mL}$ of deuterated dimethylsulfoxide ([d6] DMSO), and transfer the mixture to an NMR tube. Conduct ${ }^{1} \mathrm{H}_{-}{ }^{13} \mathrm{C}$ HSQC (measurement time $220 \mathrm{~min}$ ) NMR measurements using a $400 \mathrm{MHz}$ spectrometer.

2. Determine the types of linkages present in the lignin using the spectrum.

1. Reference the chemical shift of the spectrum to the DMSO signal $\left(\delta\left({ }^{1} \mathrm{H}\right)=2.500 \mathrm{ppm} ; \delta\left({ }^{13} \mathrm{C}\right)=\right.$ $39.52 \mathrm{ppm})$.

2. Perform a manual phase correction on both axes until all the signals are positive, then perform a baseline correction.

3. Integrate the signals of the aromatic units and the linkages of the lignin; see Table 1 for the chemical shifts.

3. Calculate the sum of the aromatic units (arom.) using the following formula:

$\Sigma($ arom. $)=\left(\mathrm{S}_{2,6} / 2\right)+\left(\left(\mathrm{G}_{2}+\mathrm{G}_{5}\right) / 2\right)+\left(\mathrm{H}_{2,6} / 2\right)(1)$ With $S_{i}$ being the integral over the signal corresponding to the 2 and 6 syringyl protons, $G_{i}$ being the integrals over the signals corresponding to the 2 and 5 guaiacyl protons, and $\mathrm{H}_{i}$ being the integral over the signal corresponding to the 2 and 6 p-hydroxyphenyl protons. 
4. Calculate the percentage of each unit using the following formulas:

$$
\begin{aligned}
& S=\left(S_{2,6} / 2\right) / \Sigma(\text { arom. }) \times 100 \%(2) \\
& G=\left(\left(G_{2}+G_{5}\right) / 2\right) / \Sigma(\text { arom. }) \times 100 \%(3) \\
& H=\left(H_{2,6} / 2\right) / \Sigma(\text { arom. }) \times 100 \%(4)
\end{aligned}
$$

With $\mathrm{S}, \mathrm{G}$, and $\mathrm{H}$ being the percentages of respective monomers-syringyl- (S), guaiacyl- $(G)$, and p-hydroxyphenyl $(\mathrm{H})$-monomer units per 100 monomer units.

5. Calculate the number of linkages per 100 units using the following formulas:

$\beta$-O-4 linkages $=\alpha \beta-O-4 / \Sigma($ arom. $) \times 100 \%(5)$

linkages $=(\alpha \beta-\beta+\beta \beta-\beta+\gamma \beta-\beta) / \Sigma($ arom. $) \times 100 \%$ (6)

linkages $=(\alpha \beta-5+\beta \beta-5+\gamma \beta-5) / \Sigma($ arom. $) \times 100 \%$ (7)

With $\alpha, \beta$, and $y$ being the integral over the signal corresponding to the $\alpha-, \beta$ - and $\gamma$-proton signals of the corresponding $\beta-O-4-, \beta-\beta$ - and $\beta-5$ linkages.

NOTE: Linkages are given as linkage per 100 monomer units. Due to overlapping of peaks, $\beta-O-4$ is calculated using only the $\alpha$ proton signal. $\beta-\beta$ and $\beta-5$ linkages are calculated using all signals of the corresponding linkage.

3. Gel permeation chromatography (GPC) analysis

1. Dissolve $10 \mathrm{mg}$ of dried lignin and $1 \mathrm{mg}$ of glucose (as internal standard) in $1 \mathrm{~mL}$ of a $0.1 \mathrm{M} \mathrm{NaOH}$ and $0.01 \mathrm{wt} \% \mathrm{NaN}_{3}$ aqueous solution in a $1.5 \mathrm{~mL}$ gas chromatography (GC)-vial. Close the GC-vial using a cap with septum.

2. Inject $100 \mu \mathrm{L}$ of the sample into a high-performance liquid chromatography (HPLC) system equipped with an ultraviolet detector and monitoring a wavelength of $\lambda=280 \mathrm{~nm}$. Use a system consisting of a precolumn programmed-temperature split/ splitless injector system with polar silica $(8 \mathrm{~mm} \times$ $50 \mathrm{~mm})$ and three gel columns $(8 \mathrm{~mm} \times 300 \mathrm{~mm}$, particle diameter: $5 \mu \mathrm{m}$, nominal pore width: 1000 A) at a flow rate of $1 \mathrm{~mL} \mathrm{~min}^{-1}$. Reference the obtained data to the signal of the internal standard (glucose). Calculate the mass distribution using the software, referenced to an external calibration with poly(styrene sulfonate) in a range from 266 to 65000 Da.

4. Furfural quantification via GC

1. Add $20 \mathrm{mg} n$-decane as internal standard to the organic phase of the OrganoCat pretreatment. Transfer $1 \mathrm{~mL}$ of the organic phase into a $1.5 \mathrm{~mL}$ GC-vial.

2. Inject $1 \mu \mathrm{L}$ of this solution into a gas chromatograph using a $30 \mathrm{~m}$ column with a polar polyurethane glycol stationary phase and helium as the carrier gas with a flow rate of $1.5 \mathrm{~mL} \mathrm{~min} \mathrm{~m}^{-1}$ and a flame-ionization detector. Set the initial temperature to $50{ }^{\circ} \mathrm{C}$, then raise by $8^{\circ} \mathrm{C} \mathrm{min}^{-1}$ to $250{ }^{\circ} \mathrm{C}$ and maintain at 250 ${ }^{\circ} \mathrm{C}$ for $5 \mathrm{~min}$.

3. Quantify furfural using the integrals (Int) given by the software and an externally calculated correction factor (cf).

1. Prepare a sample of $1 \mathrm{mg}$ of furfural and $5 \mathrm{mg}$ of $n$-decane in $1 \mathrm{~mL}$ of 2-MTHF, and inject it into the GC using the aforementioned procedure. Calculate the correction factor as follows:

$$
\begin{aligned}
& \text { cf }=(\operatorname{Int}(n \text {-decane }) \quad / \mathrm{m}(n \text {-decane })) \quad / \\
& (\text { Int(furfural) } / \operatorname{Int}(\text { furfural }))(8)
\end{aligned}
$$


2. Use the correction factor to calculate the amount of furfural in the unknown sample with the following formula: $\mathrm{m}($ furfural $)=\mathrm{m}(n$-decane $) / \operatorname{lnt}(n$-decane $) \times \mathrm{cf} \times$ Int(furfural) (9)

5. Cellulose-enriched pulp hydrolysis

1. Carry out pulp hydrolysis of cellulose-enriched residue obtained from OrganoCat pretreatment in a heating block with mixing (see the Table of Materials) using $1.5 \mathrm{~mL}$ vials.

2. Add $20 \mathrm{mg}$ of cellulose-enriched pulp and $10 \mu \mathrm{L}$ of cellulase (60 filter paper units (FPU) $\mathrm{mL}^{-1}$ and 82 cellobiase units (CBU) $\mathrm{mL}^{-1}$ ) to $1 \mathrm{~mL}$ of citrate buffer $(\mathrm{pH}=4.5)$ in a $1.5 \mathrm{~mL}$ vial, and shake at $50^{\circ} \mathrm{C}$ for 0 h, $1 \mathrm{~h}$, or $72 \mathrm{~h}$. Afterwards, heat the samples to 99 ${ }^{\circ} \mathrm{C}$ for 10 min to denature the enzymes.

3. Determine the glucose concentration using a glucose (hexokinase) assay kit.

\section{Representative Results}

A typical set of conditions for the lignocellulose pretreatment and fractionation process OrganoCat (OrganoCat) uses 0.1 M FDCA as a catalyst, a biomass loading of $100 \mathrm{~g} \mathrm{~L}^{-1}$ (beech wood, compared to the aqueous phase), $1 \mathrm{~h}$ of reaction time and $160{ }^{\circ} \mathrm{C}$ as the reaction temperature. The composition of beech wood has been published elsewhere ${ }^{21}$ ( $48 \%$ cellulose, $27 \%$ hemicellulose, $26 \%$ lignin). Figure 1 shows the extracted hemicellulose hydrolysate with this set of conditions as well as longer reaction time $(3 \mathrm{~h})$ and lower temperature $\left(140^{\circ} \mathrm{C}\right)$.

Using harsher conditions, e.g., higher temperature and longer reaction time, might lead to higher extraction yields, but also leads to more degradation of the productsfurfural is a degradation product of xylose, whereas 5-(hydroxymethyl)furfural (5-HMF) is the corresponding degradation product of glucose. A higher amount of furfural was noted in the products (distributed between the aqueous and the organic phases) with a reaction time of $3 \mathrm{~h}$ at 160 ${ }^{\circ} \mathrm{C}$. As the sugar degradation products are highly reactive and tend to form humins-oligomers of furans and sugarsthe shorter reaction time at higher temperature might be considered a good compromise between high extraction efficiency and low sugar degradation.

The amount of extracted lignin is directly related to the reaction temperature and time as well. Figure $\mathbf{2}$ displays the amount of lignin extracted, the $\beta-O-4$-linkage content, and the mass-average molar masses of the extracted lignins. While the extracted lignin yield rises with longer reaction time, the number of intact $\beta$-O-4-linkages diminishes by approximately half when reacting for $3 \mathrm{~h}$ instead of $1 \mathrm{~h}$. Lowering the reaction temperature from $160{ }^{\circ} \mathrm{C}$ to $140{ }^{\circ} \mathrm{C}$ has a much lower impact on lignin, resulting in slightly less yield, smaller mass-average molar mass, and higher $\beta-O-4-$ content.

As enzymatic hydrolysis of (lingo-)cellulose is a common indicator for pulping efficiency, a commercial cellulose cocktail was applied to the different OrganoCat pulps resulting from the above mentioned OrganoCat reaction condition sets (Figure 3). As the cellulase is not optimized for the substrates, the overall cellulose conversion is not comparable to stateof-the-art performance; however, it allows the comparison of the different pulps to each other. The longer reaction time exhibits a significant impact on the initial reaction time and the glucose yield after $72 \mathrm{~h}$, improving by a factor of $\sim 2.5$. Lowering the temperature appears to show a much smaller impact, implying that the main factor causing the differences 
in enzymatic digestibility within this treatment is the degree of delignification.

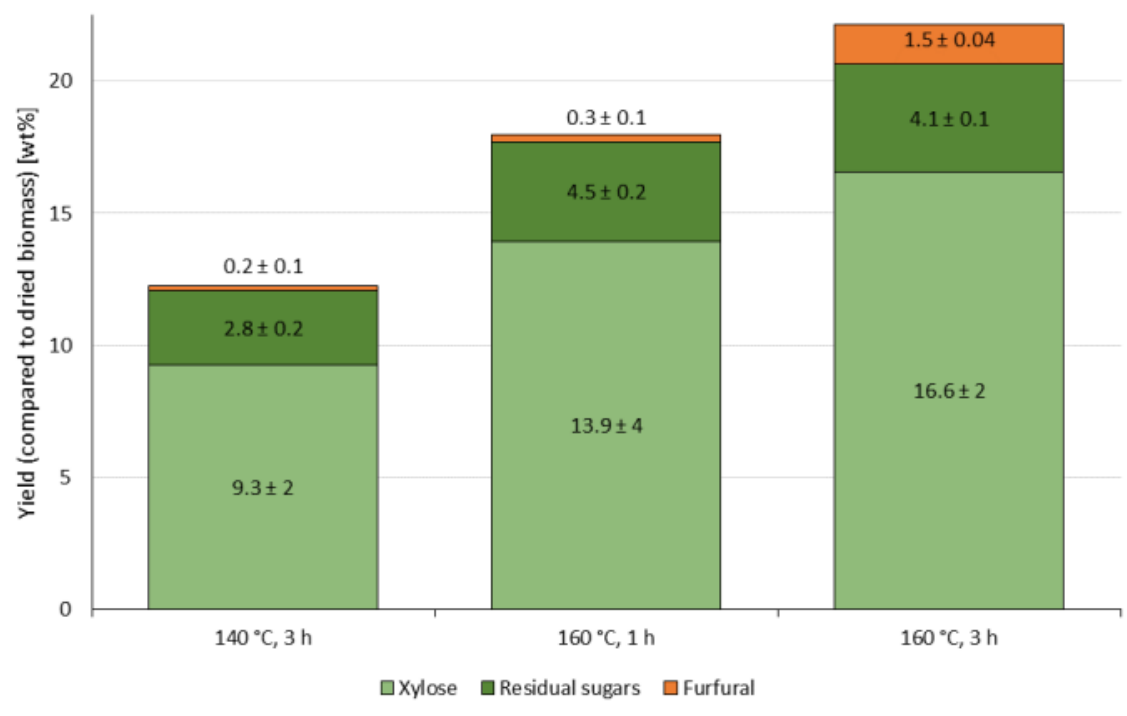

Figure 1: Sugar extraction and furfural production in OrganoCat process with $0.1 \mathrm{M} 2,5$-furandicarboxylic acid as catalyst and $100 \mathrm{~g} \mathrm{~L}^{-1}$ beech wood (compared to the aqueous phase) at different reaction temperatures and times as indicated on the $x$-axis ${ }^{11}$. All experiments have been performed in triplicate. The average is shown with the standard deviation. Please click here to view a larger version of this figure. 


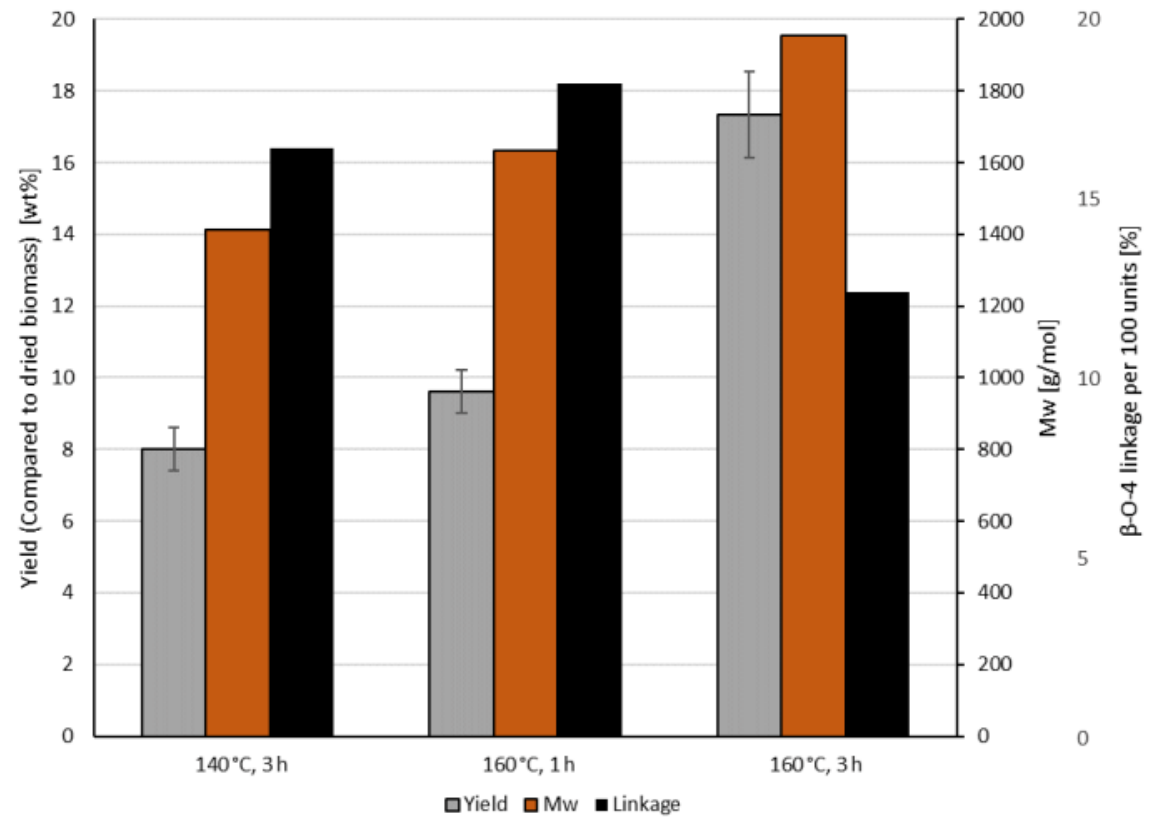

Figure 2: Amount and analysis of lignin extracted by OrganoCat process with $0.1 \mathrm{M} 2,5$-furandicarboxylic acid as catalyst and $100 \mathrm{~g} \mathrm{~L}^{-1}$ beech wood (compared to the aqueous phase) at different reaction temperatures and times as indicated on the $x$-axis ${ }^{11}$. Lignin yields have been calculated in triplicate. The average is shown with the standard deviation. Molecular mass and linkages were derived from representative single experiments. Please click here to view a larger version of this figure. 


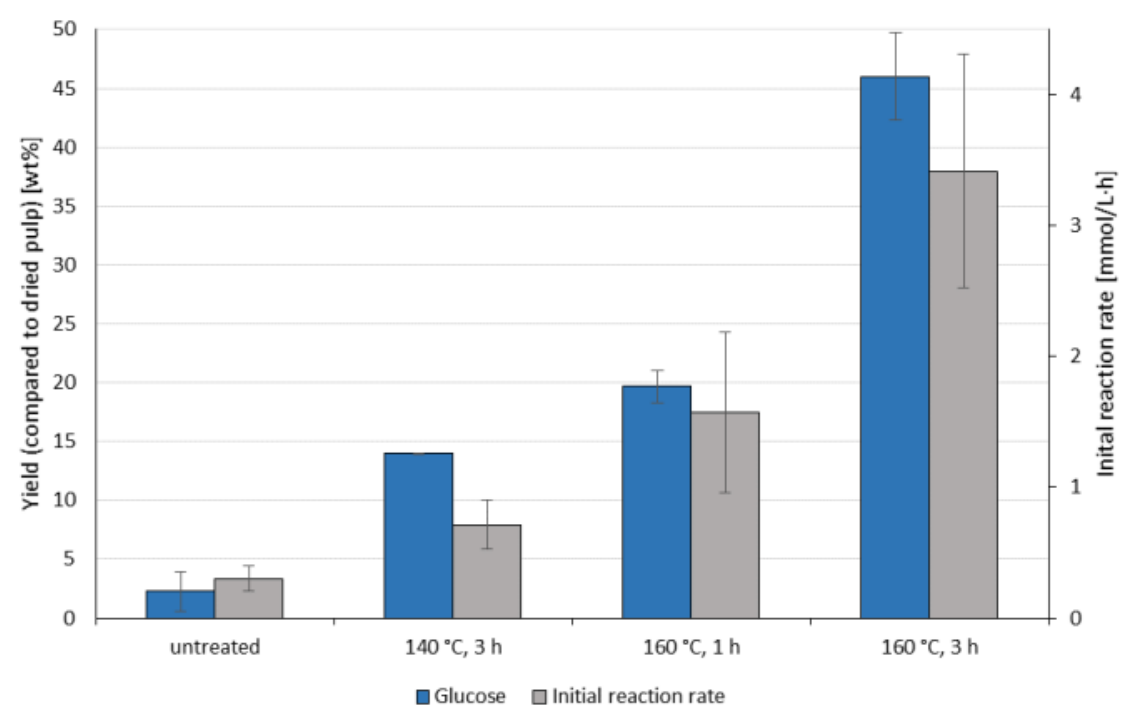

Figure 3: Enzymatic hydrolysis of pulps. Glucose yields after $72 \mathrm{~h}$ (blue bars) and reaction rates within the first hour (gray bars) from the hydrolysis of untreated beech wood and cellulose-enriched pulps obtained from OrganoCat with 0.1 M 2,5-furandicarboxylic acid as catalyst and $100 \mathrm{~g} \mathrm{~L}^{-1}$ beech wood (compared to the aqueous phase) at different reaction temperatures and times as indicated on the x-axis. Cellulase was applied to the different substrates at $50{ }^{\circ} \mathrm{C}$ for up to 72 $\mathrm{h}$ in contrite buffer $(\mathrm{pH} 4.5)^{11}$. All experiments have been performed in triplicate. The average is shown with the standard deviation. Please click here to view a larger version of this figure. 


\begin{tabular}{|c|c|c|c|}
\hline Unit & Shift $\delta\left({ }^{1} \mathrm{H}\right)\left({ }^{13} \mathrm{C}\right)$ & Linkage & Shift $\delta\left({ }^{1} \mathrm{H}\right)\left({ }^{13} \mathrm{C}\right)$ \\
\hline & {$[\mathrm{ppm}]$} & $\alpha \beta-0-4$ & $(5.08-4.69)(75.8-69.9)$ \\
\hline$S_{2,6}$ & $(6.95-6.46)(106.8-101.9)$ & $\alpha \beta-\beta$ & $(4.72-4.58)(87.46-84.0)$ \\
\hline $\mathrm{G}_{2}$ & $(7.12-6.72)(113.4-108.7)$ & $\beta \beta-\beta$ & $(3.35-3.11)(62.0-57.9)$ \\
\hline $\mathrm{G}_{5}$ & $(7.04-6.51)(117.8-113.4)$ & $\mathrm{V} \beta-\beta 1$ & $(4.26-4.09)(73.0-70.0)$ \\
\hline $\mathrm{H}_{2,6}$ & $(7.01-6.8)(129.1-123.2)$ & $\gamma \beta-\beta 2$ & $(3.87-3.71)(73.0-70.0)$ \\
\hline & & $\alpha \beta-5$ & $(5.51-5.41)(88.8-86.6)$ \\
\hline & & $\beta \beta-5$ & $(3.52-3.42)(54.0-52.1)$ \\
\hline & & $\gamma \beta-5$ & $(3.80-3.67)(64.1-62.1)$ \\
\hline
\end{tabular}

Table 1: Chemical shifts determined by ${ }^{1} \mathrm{H}-{ }^{13} \mathrm{C}$ heteronuclear single quantum correlation nuclear magnetic resonance $\left({ }^{1} \mathrm{H}-{ }^{13} \mathrm{C}-\mathrm{HSQC}\right.$ NMR$)$ for different linkages in lignin. Abbreviations: $\mathrm{S}=$ syringyl unit, $\mathrm{G}=$ guaiacyl unit, $\mathrm{H}=p$ hydroxyphenyl unit.

\section{Discussion}

The described fractionation of lignocellulose shows a tradeoff between hemicellulose hydrolysis efficiency and selectivity to avoid sugar degradation to furans, depending on reaction time and temperature (Figure 1). Lignin extraction was similarly affected by the harsher conditions. Especially the reduction of $\beta$-O-4-linkages and enhancement of mass average molecular weight due to recondensation at higher temperature and reaction time underlines this compromise that must be made. The selection of reaction time and temperature is therefore a critical step in this lignocellulose fractionation process. As the efficiency of enzymatic hydrolysis appears to be mostly determined by delignification in the FDCA-catalyzed OrganoCat process, the harshest processing conditions afford the most accessible pulp. Other variations of the process $9,11,18,22$, e.g., using different catalysts, show that the strength of the catalyst and the final $\mathrm{pH}$ in the reactive solution have the strongest effect on process efficiency. Modifications of the procedure, e.g., preswelling with phosphoric acid, have been shown to have a beneficial effect as well ${ }^{22}$. Due to the variety in composition, however, the process needs optimization, depending on the different feedstocks ${ }^{21}$. Considering the overall process performance, downstream purification of the separated fractions must be considered, which is why selectivity plays a major role. Compared to other organosolvlike processes, OrganoCat uses a biphasic water/2-MTHF system, which affords the major components in three relatively straightforward, separate streams. This way, further downstream and resulting energy and equipment costs can be reduced ${ }^{13,18}$. 


\section{Disclosures}

The authors have nothing to disclose.

\section{Acknowledgments}

This work was carried out as part of the Cluster of Excellence "Tailor-Made Fuels from Biomass" and "Fuel Science Center", which are funded by the Excellence Initiative of the German Research Foundation to promote science and research at German universities, as well as part of the Bioeconomy Science Center (BioSC), supported in the project $\mathrm{AP}^{3}$ Focus Lab. The scientific activities of the Bioeconomy Science Center were financially supported by the Ministry of Innovation, Science, and Research within the framework of the NRW Strategieprojekt BioSC (no. 313/323-400-002 13).

\section{References}

1. Isikgor, F. H., Becer, C. R. Lignocellulosic biomass: a sustainable platform for the production of bio-based chemicals and polymers. Polymer Chemistry. 6 (25), 4497-4559 (2015).

2. Azadi, P., Inderwildi, O. R., Farnood, R., King, D. A. Liquid fuels, hydrogen and chemicals from lignin: A critical review. Renewable \& Sustainable Energy Reviews. 21, 506-523 (2013).

3. Aro, T., Fatehi, P. Production and application of lignosulfonates and sulfonated lignin. ChemSusChem. 10 (9), 1861-1877 (2017).

4. Kai, D. et al. Towards lignin-based functional materials in a sustainable world. Green Chemistry. 18 (5), 1175-1200 (2016).
5. Fang, W., Yang, S., Wang, X. -L., Yuan, T. -Q., Sun, R. -C. Manufacture and application of lignin-based carbon fibers (LCFs) and lignin-based carbon nanofibers (LCNFs). Green Chemistry. 19 (8), 1794-1827 (2017).

6. Linger, J. G. et al. Lignin valorization through integrated biological funneling and chemical catalysis. Proceedings of the National Academy of Sciences of the United States of America. 111 (33), 12013-12018 (2014).

7. Liao, Y. et al. A sustainable wood biorefinery for lowcarbon footprint chemicals production. Science. 367 (6484), 1385-1390 (2020).

8. Galkin, M. V., Samec, J. S. M. Lignin valorization through catalytic lignocellulose fractionation: a fundamental platform for the future biorefinery. ChemSusChem. 9 (13), 1544-1558 (2016).

9. vom Stein, T. et al. From biomass to feedstock: onestep fractionation of lignocellulose components by the selective organic acid-catalyzed depolymerization of hemicellulose in a biphasic system. Green Chemistry. 13 (7), 1772-1777 (2011).

10. Anastas, P. T. Meeting the challenges to sustainability through green chemistry. Green Chemistry. 5 (2), G29G34 (2003).

11. Weidener, D. et al. One-step lignocellulose fractionation by using 2,5-furandicarboxylic acid as a biogenic and recyclable catalyst. ChemSusChem. 11 (13), 2051-2056 (2018).

12. vom Stein, T., Grande, P. M., Leitner, W., Domínguez de María, P. Iron-catalyzed furfural production in biobased biphasic systems: from pure sugars to direct use of crude xylose effluents as feedstock. ChemSusChem. 4 (11), 1592-1594 (2011). 
13. Viell, J., Harwardt, A., Seiler, J., Marquardt, W. Is biomass fractionation by Organosolv-like processes economically viable? A conceptual design study. Bioresource Technology. 150, 89-97 (2013).

14. Ait Rass, H., Essayem, N., Besson, M. Selective aerobic oxidation of 5-HMF into 2,5-furandicarboxylic acid with $\mathrm{Pt}$ catalysts supported on $\mathrm{TiO}_{2}$ - and $\mathrm{ZrO}_{2}$-based supports. ChemSusChem. 8 (7), 1206-1217 (2015).

15. Yi, G., Teong, S. P., Zhang, Y. Base-free conversion of 5-hydroxymethylfurfural to 2,5-furandicarboxylic acid over a Ru/C catalyst. Green Chemistry. 18 (4), 979-983 (2016).

16. Ardemani, L. et al. Solid base catalysed 5-HMF oxidation to 2,5-FDCA over Au/hydrotalcites: fact or fiction? Chemical Science. 6 (8), 4940-4945 (2015).

17. Domínguez de María, P., Guajardo, N. Biocatalytic valorization of furans: opportunities for inherently unstable substrates. ChemSusChem. 10 (21), 4123-4134 (2017).

18. Grande, P. M. et al. Fractionation of lignocellulosic biomass using the OrganoCat process. Green Chemistry. 17 (6), 3533-3539 (2015).

19. Holtz, A. et al. Process development for separation of lignin from OrganoCat lignocellulose fractionation using antisolvent precipitation. Separation and Purification Technology. 236, 116295 (2020).

20. Weidener, D. et al. Lignin precipitation and fractionation from OrganoCat pulping to obtain lignin with different sizes and chemical composition. Molecules. 25 (15), 3330 (2020).

21. Weidener, D. et al. Multiscale analysis of lignocellulose recalcitrance towards OrganoCat pretreatment and fractionation. Biotechnology for Biofuels. 13 (1), 155 (2020).

22. Weidener, D. et al. Lignocellulose fractionation using recyclable phosphoric acid: lignin, cellulose, and furfural production. ChemSusChem. 14 (3), 909-916 (2020). 